\title{
GLUCURONIDASE ACTIVITY OF ESCHERICHIA COLI ISOLATED FROM CHICKEN CARCASSES
}

\author{
Luana Martins Perin; Anderson Keizo Yamazi; Paula Mendonça Moraes; Marcus Vinícius Coutinho Cossi; Paulo Sérgio \\ de Arruda Pinto; Luís Augusto Nero*
}

Universidade Federal de Viçosa, Departamento de Veterinária, Viçosa, MG, Brasil.

Submitted: August 27, 2009; Returned to authors for corrections: March 01, 2010; Approved: March 29, 2010.

\begin{abstract}
To identify Escherichia coli through the production of $\beta$-D-glucuronidase (GUD), 622 suspect cultures were isolated from chicken carcasses and plated in Petrifilm ${ }^{\mathrm{TM}}$ EC. Of these cultures, only 44 (7.1\%) failed to produce GUD. This result indicates the usefulness of GUD production for estimating E. coli populations in chicken.
\end{abstract}

Key words: Escherichia coli, glucuronidase activity, chicken

Research on food hygiene indicator microorganisms is commonly used to obtain information about the conditions of food production, storage, transport and processing (6). Because they are usually present in the intestinal microbiota of warmblooded animals, microorganisms of the E. coli species are important hygiene indicators as they suggest direct or indirect contamination by fecal material (7). The study of this microorganism in chickens is important because the presence of $E$. coli indicates a lack of hygiene during production and a failure in processing the carcasses. A rupture of the intestines, for example, or inappropriate handling during storage and postprocessing operations (4) can cause contamination by E. coli.

The food industry needs reliable tests to detect and quantify $E$. coli in products of animal origin. The procedure conventionally employed to detect and enumerate this microorganism is the Multiple Tube Technique (MTT), which uses several selective culture media to isolate the microorganisms. After being isolated, the suspect cultures must be biochemically identified using several laboratory tests. This procedure is highly sensitive, but it is laborious and usually takes three to six days to provide a final result (3).

Alternatively, several detection methods based on specific characteristics of $E$. coli, such as the detection of glucuronidase activity (9), are widely employed in microbiological analyses. The $\beta$-D-glucuronidase (GUD) enzyme is produced by 94 $96 \%$ of E. coli strains. For this reason, the presence of GUD is useful in identifying this species. This enzymatic identification technique is the basis of Petrifilm ${ }^{\mathrm{TM}}$ EC (3M Microbiology, St. Paul, MN, USA). In Petrifilm ${ }^{\mathrm{TM}} \mathrm{EC}$, colonies of E. coli typically present a blue color associated with gas production. This test is useful for confirming suspect cultures as it is highly practical and readily available, thereby allowing a direct enumeration of $E$. coli present in the food sample.

This work aims to identify the ability of suspect $E$. coli cultures that have been isolated from chicken carcasses to produce GUD, including determining the occurrence of GUDpositive and negative $E$. coli. The goal is to evaluate whether methods based on the identification of glucuronidase activity could be safely used to estimate populations of this microorganism.

\footnotetext{
*Corresponding Author. Mailing address: Departamento de Veterinária, Universidade Federal de Viçosa, Campus Universitário, 36570-000, Viçosa, MG, Brazil.; Tel.: + 553138991463 fax: + 55313899 1457.; E-mail address: nero@ufv.br
} 
Superficial samples of 120 chicken carcasses at different stages of processing were collected from a slaughterhouse located in Viçosa, MG. The carcasses were submitted to an enumeration of total and thermotolerant coliforms using the MTT (2, 5). At the confirmation stage of thermotolerant coliforms, the cultures that presented positive results (turbidity of the EC culture media after incubation at $44.5^{\circ} \mathrm{C}$ for $24-48 \mathrm{~h}$ and gas formation) were streaked in Eosin Methylene Blue (EMB) plates. The cultures were then incubated at $35{ }^{\circ} \mathrm{C}$ for 24-48 h. Cultures that presented colonies with the typical $E$. coli morphology and color, with a black center presenting or not a greenish metallic brightness (8), were purified after successive streaks in EMB. These cultures were then inoculated in Tryptic Soy Broth (TSB) and incubated at $35^{\circ} \mathrm{C}$ for $24 \mathrm{~h}$. Next, the cultures were streaked on Petrifilm ${ }^{\mathrm{TM}} \mathrm{EC}$ plates (3M Microbiology) that had been hydrated with $1 \mathrm{~mL}$ of $\mathrm{NaCl} 0.85 \%$. The cultures were then incubated at $35^{\circ} \mathrm{C}$ for $24-$ $48 \mathrm{~h}$ to verify the glucuronidase activity of the suspect cultures, which is identified by the formation of blue colonies associated with gas formation. All culture media were from Oxoid Ltd.
(Basingstoke, Hampshire, England).

Based on these results, the GUD-positive and negative cultures were selected and submitted to biochemical identification using a Bactray kit (Laborclin Ltda, Pinhais, PR, Brazil). The cultures that presented a poor identification on Bactray 1 (reliability rate lower than 90\%) were submitted to complementary tests on Bactray 2.

Based on the results, we calculated the frequency of $E$. coli cultures that produced GUD.

A total of 622 cultures presented colonies with a greenish metallic brightness in the EMB agar. All of these cultures were submitted to an identification of glucuronidase activity. Out of the cultures tested, 578 (92.9\%) presented GUD production while $44(7.1 \%)$ did not. These 44 cultures produced red colonies associated with gas (Figure 1).

Based on the results, 22 GUD-positive and 35 GUDnegative cultures were selected for biochemical identification using the Bactray. All of the cultures tested were identified as E. coli, and they presented diverse biochemical profiles (Table $1)$.
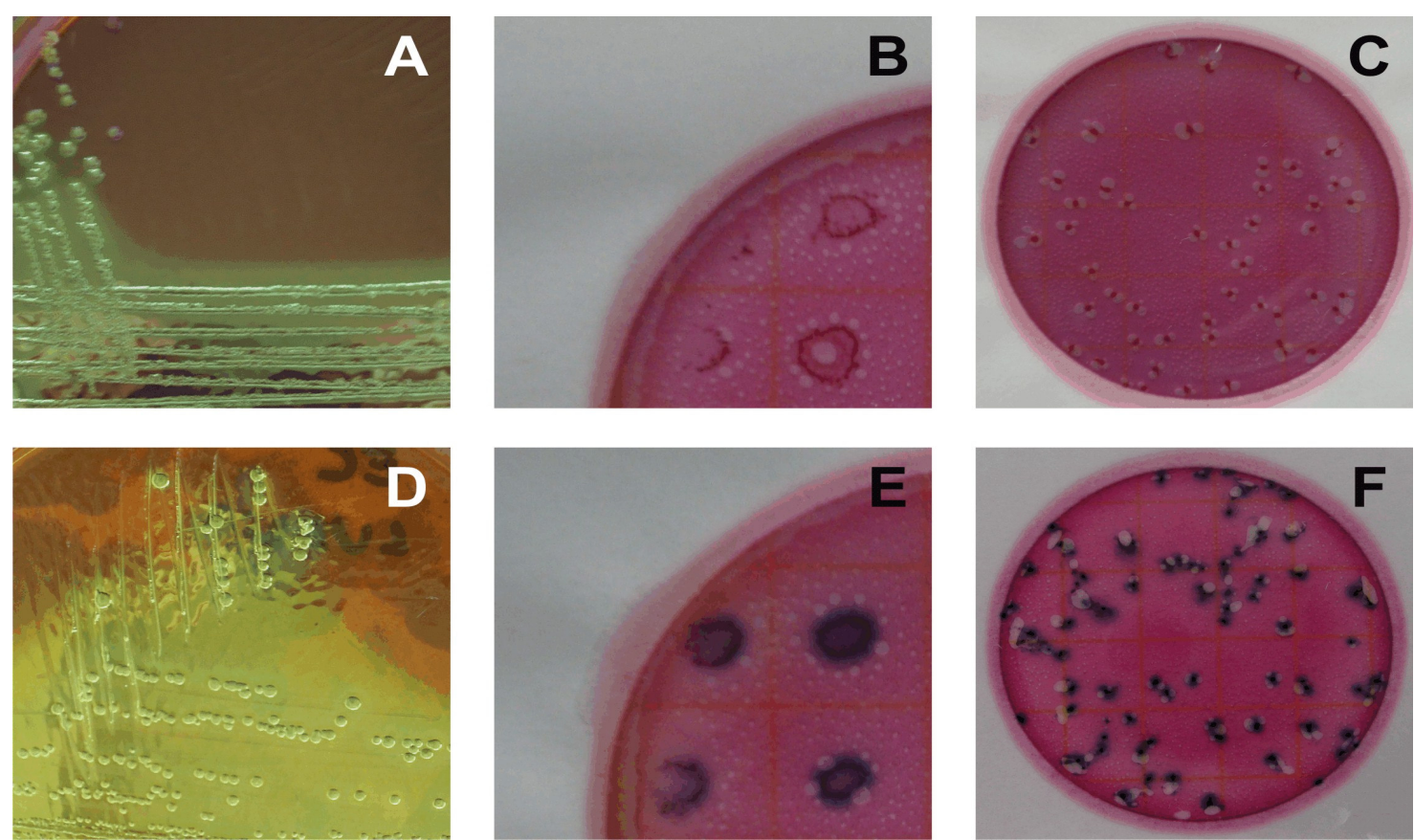

Figure 1. Morphological characteristics of two E. coli cultures isolated from chicken carcasses. A and D: GUD-negative and GUD-positive $E$. coli cultures, respectively, on Eosin Methylene Blue agar, showing their typical appearance; B and E: GUD-negative and GUD-positive E. coli cultures, respectively, streaked on Petrifilm ${ }^{\mathrm{TM}} \mathrm{EC}$; and C and F: GUD-negative and GUD-positive E. coli cultures, respectively, plated on Petrifilm ${ }^{\mathrm{TM}}$ EC. 
Table 1a. Glucuronidase Activity (Petrifilm ${ }^{\mathrm{TM}}$ EC) and biochemical identification (Bactray 1) of suspect E. coli cultures isolated from chicken carcasses.

\begin{tabular}{|c|c|c|c|c|c|c|c|c|c|c|c|c|c|c|c|}
\hline \multirow[t]{2}{*}{ Profile } & \multirow[t]{2}{*}{$\mathbf{n}$} & \multirow[t]{2}{*}{$\%$} & \multirow{2}{*}{$\begin{array}{l}\text { Petrifilm EC* } \\
\text { GUD }\end{array}$} & \multicolumn{10}{|c|}{ Bactray $1 * *$} & \multirow[t]{2}{*}{ Identification } & \multirow[t]{2}{*}{ Confidence(\%) } \\
\hline & & & & ONPG & ADH & LDH & ODC & $\mathbf{H}_{2} \mathrm{~S}$ & URE & $\mathbf{V P}$ & PD & IND & CIT & & \\
\hline 1 & 17 & 29.8 & - & + & - & + & + & - & - & - & - & + & - & Escherichia coli & 37.1 \\
\hline 2 & 16 & 28.1 & - & + & - & + & - & - & - & - & - & + & - & Escherichia coli & 99.9 \\
\hline 3 & 10 & 17.5 & + & + & - & + & + & - & - & - & - & + & - & Escherichia coli & 37.1 \\
\hline 4 & 1 & 1.8 & + & + & - & + & + & + & + & - & - & + & + & Escherichia coli & 100.0 \\
\hline 5 & 8 & 14.0 & + & + & - & + & - & - & - & - & - & + & - & Escherichia coli & 99.9 \\
\hline 6 & 1 & 1.8 & - & + & - & + & - & + & - & - & - & + & - & Escherichia coli & 99.9 \\
\hline 7 & 1 & 1.8 & + & + & - & + & + & + & - & - & - & + & - & Escherichia coli & 99.3 \\
\hline 8 & 1 & 1.8 & - & + & - & + & + & + & - & - & - & + & - & Escherichia coli & 99.3 \\
\hline 9 & 1 & 1.8 & + & + & - & + & - & - & - & - & - & + & + & Escherichia coli & 33.9 \\
\hline 10 & 1 & 1.8 & + & + & - & - & - & - & - & - & - & + & - & Escherichia coli & 3.6 \\
\hline
\end{tabular}

*GUD: $\beta$-D-glucuronidase.

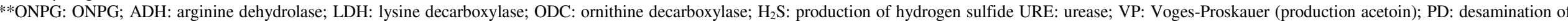
phenylalanine; IND: indole; CIT: Simmons citrate. 
Table 1b. Complementary biochemical identification (Bactray 2) of suspect E. coli cultures isolated from chicken carcasses considering previous biochemical profiles (Table 1a).

\begin{tabular}{|c|c|c|c|c|c|c|c|c|c|c|c|c|c|c|c|}
\hline \multicolumn{2}{|c|}{ Profiles* } & \multirow[t]{2}{*}{$\mathbf{n}$} & \multirow[t]{2}{*}{$\%$} & \multicolumn{10}{|c|}{ Bactray 2** } & \multirow[t]{2}{*}{ Identification } & \multirow[t]{2}{*}{ Confidence(\%) } \\
\hline Table & Bac 2 & & & MAL & RHA & ADO & SAL & ARA & INO & SOR & SAC & MAN & RAF & & \\
\hline 1 & 1 & 14 & 53.8 & - & + & - & - & + & - & + & + & + & + & Escherichia coli & 100 \\
\hline 3 & 2 & 6 & 23.1 & - & + & - & - & + & - & + & + & + & + & Escherichia coli & 100 \\
\hline 3 & 3 & 1 & 3.8 & - & + & - & - & + & - & + & - & + & + & Escherichia coli & 100 \\
\hline 1 & 4 & 1 & 3.8 & - & + & + & - & + & - & + & + & + & + & Escherichia coli & 100 \\
\hline 1 & 5 & 1 & 3.8 & - & + & - & - & + & - & - & - & - & + & Escherichia coli & 100 \\
\hline 1 & 6 & 1 & 3.8 & - & + & - & - & + & - & + & - & + & + & Escherichia coli & 100 \\
\hline 9 & 7 & 1 & 3.8 & - & + & - & - & + & - & + & + & + & + & Escherichia coli & 99.9 \\
\hline 10 & 8 & 1 & 3.8 & - & + & - & - & + & - & + & - & + & + & Escherichia coli & 95.4 \\
\hline
\end{tabular}

* Profiles based on the results of glucuronidase activity and those achieved by Bactray 1 (Table 1a) and Bactray 2 (Bac 2).

** MAL: malonate; RHA: rhamnose; ADO: adonitol; SAL: salicin; ARA: arabinose; INO: inositol; SOR: sorbitol; SAC: sucrose; MAN: mannitol; RAF: raffinose 
Because the occurrence of GUD-negative cultures was relatively low $(7.1 \%)$, it can inferred that detection methods based on GUD activity, such as Petrifilm ${ }^{\mathrm{TM}}$ EC, are valid tools for providing estimates of the quantities of this microorganism in chicken carcasses. The suitability of the Petrifilm ${ }^{\mathrm{TM}}$ system for quality control in the food industry is already well known $(1,10)$. Silva et al. (10) compared the results of E. coli obtained with Petrifilm ${ }^{\mathrm{TM}}$ EC and MTT from cheese and sausage. They found correlation coefficients between the methods of 0.77 for cheese and 0.79 for sausage, along with lower levels of contamination by MTT. Russel (11) observed a correlation coefficient of 0.95 in an evaluation of the same techniques in chicken carcasses. The results obtained in this study show that methodologies that use GUD activity to identify E. coli are important alternatives for the quality control of chicken carcasses.

All of the cultures suspected of having E. coli presented their typical morphology in the EMB agar, indicating that this characteristic can be fully associated with this species and thus highly useful in its identification. The presence of $E$. coli cultures unable to produce GUD was confirmed in some of the cultures isolated from the chicken carcasses, as previously described by Manafi (9). Nevertheless, because the occurrence of these cultures was low, they probably would not significantly affect the numerous methodologies that use glucuronidase activity to identify $E$. coli colonies. These methodologies are therefore important alternatives in monitoring this microorganism in chicken carcasses and are useful in quality control programs in poultry slaughterhouses.

\section{ACKNOWLEDGEMENTS}

L.A. Nero is supported by FAPEMIG (CVZ-PPM-00093-
09) and CNPq (303834/2009-9).

\section{REFERENCES}

1. Beuchat, L.; Copeland, R.F.; Curiale, M.S. (1998). Comparison of the Simplate ${ }^{\mathrm{TM}}$ total plate count method with Petrifilm ${ }^{\mathrm{TM}}$, Redigel ${ }^{\mathrm{TM}}$ and conventional pour-plate methods for enumerating aerobic microorganisms in foods. J. Food Prot. 61, 14-18.

2. Brasil, Ministério da Agricultura, Pecuária e Abastecimento. (2003). Oficializa os métodos analíticos oficiais para análises microbiológicas para controle de produtos de origem animal e água. Diário Oficial da União. Instrução Normativa 62, de 18 agosto de 2003.

3. de Boer, E. (1998). Update on media for isolation of Enterobacteriaceae from foods. Int. J. Food Microb. 45, 43-53.

4. de Sousa, G.B.; Tamagnini, L.M.; Olmos, P.D.; Gonzalez, R.D. (2002). Microbial enumeration in ready-to-eat foods and their relationship to good manufacturing practice. J. Food Safety 22, 27-38.

5. FDA - Food and Drug Administration. (2009). Bacteriological Analytical Manual Online. Food and Drug Association, Washington. Available at: http://www.cfsan.fda.gov/ ebam/bam-4.html. Accessed on march 3, 2009.

6. ICMSF - International Commission on Microbiological Specifications for Foods. (1986). Microorganisms in Foods 2. Sampling for microbiological analysis: Principles and specific applications. Blackwell Scientific Publications.

7. Jay, J.M.; Loessener, M.J.; Golden, D.A. (2005). Modern Food Microbiology. Springer.

8. Kornaki, J.L.; Jonhson, J.L. (2001). Enterobacteriaceae, coliforms and Escherichia coli as quality and safety indicators. In: Downes, F.P., Ito, K. (eds). Compendium of methods for the microbiological examination of foods. American Public Health Association, Washington, USA, p. 69-82.

9. Manafi, M. (2000). New developments in chromogenic and fluorogenic culture media. Int. J. Food Microb. 60, 205-218.

10. Silva, M.P.; Cavalli, D.R.; Oliveira, T.C.R.M. (2006). Avaliação do padrão coliformes a $45^{\circ} \mathrm{C}$ e comparação da eficiência das técnicas dos tubos múltiplos e Petrifilm EC na detecção de coliformes totais e Escherichia coli em alimentos. Cienc. Tecnol. Aliment. 26 (2), 352-359.

11. Russell, M.S. (2000). Comparison of the Traditional Three Most Probable Number method with the Petrifilm, Simplate, Biosys Optical and Bactometer Conductance methods for enumerating E. coli from chicken carcasses and ground beef. J. Food Prot. 63, 1179-1183. 